\title{
«HÍADES», UN PROYECTO PARA LA RECUPERACIÓN DE LA HISTORIA DE LA ENFERMERÍA
}

\author{
antonio Claret García Martinez \\ Doctor en Historia \\ Profesor de Paleografia de la Universidad de Huelva \\ Manuel Jesús García Martínez \\ Enfermero. Licenciado en Antropología \\ Profesor de Ética y Bivética. E.U. Ciencias de la Salud. Universidad de Sevilla
}

\section{RESUMEN}

En este artículo, los autores describen la evolución de la revista "Híades", la única publicación periódica dedicada exclusivamente a la historia de la enfermería en España.

Palabras clave: historia de la enfermeria.

\section{SUMMARY}

In this article the authors describe the evolution of the journal "Hiades", the only periodic publication dedicated exclusively to nursing history in Spain.

Keywords: Nursing History.

\section{I.- Introducción}

\section{II.- Orígenes y definición del proyecto Híades}

1) Momento y lugar de nacimiento del proyecto Hiades.

2) Respuestas a necesidades de la profesión enfermera.

2.1. - Desarrollo de la Historia de la Enfermería como complemento necesario para la formación integral de los enfermeros.

2.2.- Carencia de trabajos de Historia específicos de Enfermería para la formación académica.

2.3.- Inexistencia de publicaciones periódicas para el desarrollo de la historia de la disciplina.
2.4.- Dispersión y desconexión entre los investigadores de la Historia de la Enfermería.

\section{III.- Objetivos de Híades}

- Creación de un espacio permanente de reflexión en torno a la Historia de la Enfermería.

- Publicación de trabajos especializados de Historia de la Enfermería.

- Edición de una publicación periódica que sirva de referencia constante a los investigadores, docentes y lectores interesados en general.

- Coordinación de esfuerzos de distintos especialistas en la disciplina.

\section{IV.- Estructura de Hiades}

1) Publicación de trabajos monográficos sobre Historia de la Enfermería.

2) Edición de fuentes.

3) Recopilación y recensiones bibliogräficas.

4) Reflexiones epistemológicas (de fundamento y método) de la Historia de la Enfermería.

5) Información general de actividades sobre Historia de la Enfermería.

\section{V.- Conclusiones}

\section{I.- Introducción}

La puesta en marcha de todo proyecto abre un espacio de incertidumbre entre sus promotores que sólo el paso del tiempo y el logro de los objetivos previstos ayudan a esclarecer en cierta medj- 
da. Un proyecto editorial, como es la edición de una publicación periódica, sea de la disciplina que sea, representa un continuo volver a empezar, pues nada más salido de imprenta un número ha de ponerse en marcha toda la maquinaria organizativa para comenzar la gestación y feliz alumbramiento del número siguiente. Ello es el resultado, sin lugar a dudas, del esfuerzo de muchas personas que, desde las parcelas organizativa e investigadora, ofrecen su colaboración en dicho proyecto. Hiades. Revista de Historia de la Enfermeria, no es una excepción a este respecto, y desde sus origenes ha necesitado de las energias de un numeroso grupo de personas que ha hecho posible el que hoy haya seis números en las bibliotecas y en prensa el séptimo!.

\section{II.- Orígenes y definición del proyecto Hiades}

Pero la puesta en marcha de un proyecto editorial de la naturaleza de una publicación periódica cuenta habitualmente con un entorno de investigación en el seno del cual han surgido preguntas, se han desarrollado reflexiones, se han valorado energías, $y$, como motor fundamental, se va forjando una fe en la consecución de los objetivos propuestos. En definitiva, han confluido una serie de circunstancias que han madurado hasta el punto de dar forma definida a dicho proyecto editorial.

La necesidad de contextualizar la actividad enfermera en el espacio y en el tiempo para enten- der adecuadamente cómo surgió y qué sentido tenía, hace que la investigación histórica de la Enfermeria cuente, inexcusablemente, con especialistas de otros campos del saber que darán, en definitiva, esa visión multidisciplinar necesaria e imprescindible si se quiere profundizar de manera seria en el conocimiento del pasado de cualquier profesión u oficio. En este sentido, y como se pone de manifiesto en el Apéndice que se adjunta, Hiades ha contado desde sus origenes con la colaboración de investigadores procedentes de disciplinas como la Historia, Antropología y Sociología, entre otras ${ }^{2}$.

\section{1) Momento y lugar de nacimiento del proyecto Hiades}

Dentro de este marco de inquietudes, surgió en Alcalá de Guadaíra (Sevilla), en torno a 1992, la idea de poner en marcha una publicación periódica que complementara la actuación que se estaba haciendo sobre la Historia de la Enfermería a nivel nacional desde distintos espacios. Por una parte, en Madrid se había puesto en marcha unos años antes el Seminario Permanente para la Investigación de la Historia de la Enfermeria, coordinado por Francisca Hernández Martín (prolesora de la Universidad Complutense de Madrid), con el objetivo de aglutinar a distintos investigadores y equipos de investigación de todo el Estado español a través de la celebración de Jornadas y Congresos especializados en Historia de la profesión 3 . En la actualidad, se halla

\footnotetext{
' La periodicidad de Hiades. Revista de Historia de la Enfermeria es anual. El primer número salió de imprenta en agosto de 1994.

Entendemos que el estudio histórico de la Enfermería no debe limitarse a una mera exposición de biografias y obras destacadas o a la narración de los acontecimientos más relevantes acaecidos en cada época. Coincidimos con el profesor José María López Piñero en la necesidad de contemplar una histoire intégrale o "historia total": «Entendiendo ésta como la indagación integrada de todas las actividades humanas a través del tiempo, cada punto de vista especializado hay que considerarlo una parte aislada artificiosamente, cuyo análisis exige reconstruir la compleja red de relaciones, condicionamientos y dependencias que la unen a las demás. En este terreno, la delimitación de los campos de estudio es también convencional y las intersecciones, amplias y frecuentes». LÓPEZ PIÑERO, JOSÉ M." (2000): Breve Historia de la Medicina. Alianza Editorial, S. A. Madrid, pp. 9-10.

Las Primeras Jornadas Nacionaies de Historia de la Enfermería, tituladas La Enfermería en el siglo XX. De oficio a profesión. Los momentos del cambio, se celebraron en Madrid en 1992, y las siguientes en Albacete en 1993. A partir de esta fecha, el Seminario Permanente ha organizado cuatro congresos de ámbito nacional, teniendo como sedes Valencia (1994), Málaga (1995), Mérida (1997) y Gijón (1999). El próximo tendrá lugar en Sevilla en el mes de mayo de 2001.
} 
en fase de preparación el V Congreso Nacional de Historia de la Enfermería, que se celebrará en Sevilla en el mes de mayo de 2001.

Por otro lado, el creciente número de publicaciones sobre Historia de los cuidados y el de investigadores que iban abriendo líneas de investigación en este campo, hicieron que las revistas de Enfermería, de temática enfermera general, comenzaran a prestar una mayor atención a los trabajos de contenido histórico, tendencia que ha ido en aumento de manera significativa en los últimos años. Baste consultar las revistas Rol de Enfermeria (Barcelona), Index de Enfermeria (Granada), Hygia de Enfermería (Sevilla), Enfermeria Científica (Barcelona) y Cultura de los Cuidados. Revista de Enfermeria y Humanidades ${ }^{+}$(Alicante), por poner unos ejemplos, para poder observar esta realidad. Igualmente, se han ido poniendo en marcha distintos proyectos editoriales que tenían como finali- dad la edición de monografías o manuales de Historia de la Enfermerías, que venían a refrendar el auge que la materia estaba teniendo en el entorno enfermero. A todo ello hay que unir la consolidación en los planes de estudio de la mayoría de las Escuelas de Enfermería del país de asignaturas relacionadas con la Historia de los cuidados ${ }^{6}$ y su contemplación como materia troncal en el currículo de la futura Licenciatura de Enfermería ${ }^{7}$.

\section{2) Respuestas a necesidades de la profesión enfermera}

Sin embargo, allá por el año 92 gran parte de los acontecimientos referidos no se habian producido o estaban sólo en sus inicios, y el desarrollo de la Historia de la Enfermería presentaba una serie de carencias de primer orden que sólo con una actuación desde distintas esferas podían ser cubiertas, o por lo menos sentar las bases para conseguirlo.

+ En el editorial del primer número de Cultura de los Cuidados (primer semestre de 1997), se incide en la importancia de realizar el análisis histórico de la profesión teniendo en cuenta las distintas dimensiones que la caracteriza: antropológica, histórica y humanística: «La necesidad del conocimiento previo de las culturas como único camino para preservar los niveles mínimos de respeto y dignidad en todo abordaje investigador y/o educativo, revela, por sí misma, la dimensión pragmática del quehacer histórico, antropológico y humanístico en los cuidados enfermeros [... 1 ». Cultura de los Cuidados. Revista de Enfermeria y Humanidades, n. ${ }^{\circ} 1$. Seminario de Historia y Antropología de los Cuidados Enfermeros. Universidad de Alicante. Alicante, p. 4.

En este sentido, destacamos la aparición en los últimos años de obras como Historia de la Enfermería. Un análisis histórico de los cuidados de enfermeria (Juana Hernández Conesa); Historia de la Enfermería (José Siles González); Historia de la Enfermería en España. (Desde la Antigüedad hasta nuestros dias) (Francisca Hernández Martin, Coordinadora); Directorio de Enfermeros (Antonio C. García Martínez y otros); Cuidados psiquiátricos de Enfermeria en España - siglos XV al XX-. Una aproximación histórica (Francisco Ventosa Esquinaldo), y la reedición de otras como la del historiador de la Enfermería Cecilio Eseverri Chaverri, Historia de la Enfermería española e hispanoamericana.

" Un exponente de este interés por la historia de los cuidados por parte de algunas de las Escuelas de Enfermería es la celebración del Curso, considerado en el marco de las actividades docentes de libre configuración para el presente año académico 2000, titulado "Aproximación a la historia de la Matrona en España", ofertado por la Universidad Hispalense y realizado en la E. U. E. Virgen del Rocío (Sevilla) durante los meses de marzo a mayo, con una carga lectiva de tres créditos (dos teóricos y uno práctico).

En un reciente informe elaborado por la Conferencia Nacional de Directores de Escuelas Universitarias de Enfermería Estatales, se expone una propuesta de directrices del plan de estudios para el Segundo Ciclo de Enfermería homologado. Se destaca que la carga total de dicho Ciclo es de 120 créditos y que las materias troncales responden al 60\% aproximadamente sobre la totalidad del plan de estudio. Entre estas materias troncales se halla Historia de la Enfermeria, con una carga lectiva de $4 ' 5$ créditos, con los siguientes descriptores: "Ciencia histórica y Enfermería. Los cuidados de enfermería y la interpretación de la salud y la enfermedad en la historia. Evolución histórica de la Enfermería en los sistemas sanitarios y educativos". Igualmente se recoge en el informe que los actuales Estudios de Título Propio de Segundo Ciclo en Enfermería se imparten en las Escuelas de Enfermería de la Universidad de Alicante, Universidad de Huelva, Universidad de Tarragona y la Universidad Internacional de Barcelona. Véase CONFERENCIA NACIONAL DE DIRECTORES DE ESCUELAS UNIVERSITARIAS DE ENFERMERÍA ESTATALES: "Propuesta de Segundo Ciclo en Enfermeria". Abril de 2000. 


\section{1.- Desarrollo de la Historia de la} Enfermeria como complemento necesario para la formación integral de los enfermeros.

En los actuales planes de estudio tendentes a la consecución del título de Diplomado en Enfermería se presta escasa atención a la formación humanistica de los enfermeros y enfermeras. Gran parte de las horas de estudio se ocupan en asignaturas de contenido técnico y sólo algunas, como las de Ética, Bioética o Historia de la Enfermería, proponen otros espacios de reflexión al estudiante que les ayude a ampliar su visión, tanto de la profesión misma como del papel que el profesional de Enfermería tiene ( $y$ ha tenido) en la sociedad en la que vive. Y tanto más cuanto la tendencia actual es la de considerar al ser humano en su triple vertiente: biológica, psicológica y social.

En una sociedad como la actual, en la que la excesiva "tecnificación" del trabajo y de la vida en general, está configurando una personalidad altamente insatisfecha y carente en muchos casos de respuestas adecuadas para las nuevas necesidades psicológicas de la era de la técnica, la formación humanística de los profesionales puede ayudar al equilibrio de los desajustes producidos.

A nadie se nos escapa que el trabajo representa una de las parcelas más importantes que ocupa el ser humano y la insatisfacción en el mismo es causa frecuente de importantes desajustes emocionales en los individuos. En este sentido, el acceso al conocimiento de los orígenes de la profesión que uno desarrolla, del papel que ha jugado a lo largo de los siglos, de la valoración que los individuos han realizado de la misma y de su evolución a lo largo de los siglos, son temas unidos a la vida misma y que, como tal realidad, configuran vivencias de las que el profesional actual ocupa un eslabón más en una larga e interminable cadena. Para amar las cosas hay que conocerlas previamente; para defenderlas, hay que valorarlas.

En este sentido, hacemos nuestras las palabras del profesor Laín Entralgo", eminente historiador de la Medicina, cuando señala la necesidad de que el profesional de la Medicina -igualmente aplicable al caso de la Enfermería- conozca el desarrollo histórico de la profesión que ejerce. Adecuadamente aprendida, la historia de la Medicina ofrece al profesional:

-Un camino hacia la integridad de su saber.

-Uno de los requisitos para la posesión, en lo concerniente a sus saberes propios, de bien fundada dignidad moral.

-Una poderosa ayuda para el logro de la claridad intelectual que el ejercicio de cualquier técnica tan esencialmente pide.

-Una sutil y radical instancia para el ejercicio de la libertad de la mente.

- La formación histórica puede conceder, en fin, cierta opción a la originalidad.

2.2.- Carencia de un número importante de trabajos especificos de Historia de la Enfermeria para la formación académica.

Desde los años setenta y comienzo de los ochenta, en que salieron trabajos monográficos puntuales de Historia de la Enfermería", que han servido de referentes obligados para los interesados en la materia, las publicaciones sobre Historia de la profesión han aparecido a un ritmo muy lento, pasando la mayoría de ellos desapercibidos para un público general, incluso para los propios estudiantes de la asignatura, por la dis-

\footnotetext{
LAÍN ENTRALGO, P. (1982): Historia de la Medicina. Salvat Editores, S. A. Barcelona, pp. XXIX-XXXI.

Citamos en este apartado las obras ya clásicas de Cecilio Eseverri Chaverri (Historia de la Enfermeria Española e Hispanoamericana), Francisco Ventosa Esquinaldo (Historia de la Enfermeria Española) y Carmen Domínguez-Alcón (Los cuidados y la profesión enfermera en España; Sociologia y Enfermeria; La Infermeria a Catalunya), utilizadas como manuales de texto en la formación de los enfermeros españoles.
} 
persión de los mismos y la falta de continuidad de los temas. Habitualmente, la Historia de la Enfermería se impartía, y en gran medida se sigue haciendo hoy, tomando como referente la Historia de la Medicina, lo cual producía en nuestros estudiantes la sensación de la inexistencia de una historia propia, como si la profesión enfermera careciera de su identidad y se hubiese ido configurando a la sombra de otras profesiones, de las que ha ido frecuentemente a remolque, realidad ésta que en modo alguno se sostiene cuando nos acercamos mínimamente a la historia de la profesión con cierta profundidad y rigor.

\section{3. - Inexistencia de publicaciones periódicas para el} desarrollo de la historia de la disciplina.

En este contexto se dejaba sentir especialmente la falta de publicaciones periódicas especializadas y monográficas que sirvieran de referente para los trabajos sobre Historia de la profesión. Otras materias de la misma Enfermería - técnicas, enfermería médicoquirúrgica, atención primariacuentan desde hace ya bastantes años con espléndidas publicaciones periódicas que han hecho aportaciones muy valiosas en los distintos campos que han abordado, ayudando a definir modelos de actuación, desarrollando líneas de reflexión y aunando esfuerzos en pro de la propia profesión. En este sentido, las publicaciones periódicas aportan un sentido de continuidad siempre necesario para el mantenimiento y desarrollo de la identidad de las disciplinas. La joven disciplina de la Historia de la Enfermería carecía de este tipo de publicaciones que cubrieran estas importantes carencias.

2.4.-Dispersión y desconexión entre los investigadores de la Historia de la Enfermería.

La falta de coordinación entre los investigadores y grupos de investigación a nivel nacional, incluso en espacios geográficos más reducidos, hace que con frecuencia se gasten energías inútilmente a la hora de poner en marcha proyectos de investigación y que sus resultados sean desaprovechados por la falta de circulación de los mismos, lo cual provoca un desarrollo lento de la disciplina, cuando no el desaliento y abandono del investigador ante la sensación de soledad que experimenta. Los avances tecnológicos experimentados en los últimos años facilitan enormemente esta comunicación entre investigadores y grupos de distintas zonas geográficas del país e incluso fuera del mismo, con lo que la investigación histórica se enriquece de manera notable.

\section{III.- Objetivos de Hiades}

La puesta en marcha del proyecto Híades. Revista de Historia de la Enfermeria, venía motivada, en gran medida, por la percepción de las carencias antes referidas de un grupo de investigadores sevillanos pertenecientes a los ámbitos de la Enfermería y de la Historia, vinculados al entorno del Seminario Permanente para la Investigación de la Historia de la Enfermería, surgido en la Universidad Complutense de Madrid, y que buscaba la creación de un espacio permanente de reflexión en torno a la Historia de la Enfermería a través de la publicación de trabajos monográficos especializados en la materia y que coordinara los esfuerzos de un número cada vez mayor de investigadores de todo el territorio nacional.

Para conseguir estos objetivos se concibió la puesta en marcha de una publicación periódica con una estructura interna que abordara los espacios que creíamos fundamentales para el desarrollo de la disciplina, y que pudieran servir de referente a investigadores y docentes, por una parte, y de formación en su sentido más amplio para todo tipo de lectores. De esta manera se creó para Híades una estructura interna sustentada en cinco grandes pilares. 


\section{IV.- Estructura de Híades: cinco pilares para el desarrollo de la Historia de la Enfermería}

1) Publicación de trabajos monográficos sobre Historia de la Enfermería.

2) Edición de fuentes

3) Recopilación y recensión bibliográfica.

4) Reflexiones epistemológicas (de fundamento y método) de la Historia de la Enfermería.

5) Información General de actividades sobre Historia de la Enfermería.

La publicación de trabajos monográficos que abarcaran cronológicamente toda la historia del ser humano desde que se tienen referencias suficientes para construir una historia científica y rigurosa y abarcando todo el territorio nacional (no se descartan colaboraciones de otros ámbitos geográficos más amplios, siempre que aporten conocimientos y métodos de investigación valiosos para nuestros investigadores), mostrando los resultados de las investigaciones realizadas, bien a nivel individual, bien a nivel de grupo institucionalizado, ha permitido disponer de una valiosa información sobre el pasado de la profesión enfermera: datos sobre el trabajo enfermero en distintas épocas, su papel en las instituciones, técnicas empleadas, nivel de instrucción, etc.

La edición de fuentes escritas. Desde los inicios de su andadura, Híades ha prestado una especial atención a la edición de fuentes, tanto para uso de investigadores como de docentes, con el objeto de llamar la atención a esta parcela totalmente necesaria de la investigación histórica. De ahí que se hayan incluido sistemáticamente textos de larga extensión en los distintos números publicados ${ }^{10}$.

La recopilación y recensión bibliográfica. La puesta al día y el control de la bibliografía publicada ocupa una parcela básica para todo investigador y docente" ${ }^{11}$. Por este motivo, Híades dedica parte de sus páginas a la recopilación de bibliografía y ha creado secciones específicas para el comentario de obras históricas básicas generadas por o para enfermeros ${ }^{12}$.

En cuarto lugar, no pueden olvidarse las reflexiones epistemológicas en toda disciplina. Los ensayos sobre los fundamentos de la Historia de la Enfermería y los métodos de investigación han de estar siempre presentes para servir de apoyo o consulta a otros investigadores, cuando no a los jóvenes que se inician en su estudio e investigación.

Por último, Hiades concibió la necesidad de dar a conocer en sus páginas aquellos eventos que se producían en los que la Historia de la Enfermería tenía una destacada presencia: celebración de congresos y jornadas, convocatoria de premios, certámenes y otros eventos en donde se viera reflejado el dinamismo de la disciplina y pudieran servir de estímulo o referencia a otros profesionales $e$ investigadores.

\section{V.- Conclusiones}

En definitiva, el proyecto Hiades. Revista de Historia de la Enfermeria, nació como resultado de

\footnotetext{
10 Destacamos la publicación íntegra de la primera edición de las Reglas y Constituciones de la Mínima Congregación de los Hermanos Enfermeros Pobres, conocida popularmente como Obregones, editadas en 1634, en las que se recogen las funciones del enfermero de este Instituto (Hiades n. ${ }^{\circ}$ ), o la edición de un texto del siglo XVIII para la formación de las parteras, el cual nos sirve para conocer el nivel de formación de estas profesionales en esa época (Híades n. ${ }^{\circ}$ 5-6).

"Es importante resaltar la labor que en este campo viene realizando la revista Index de Enfermeria (Granada), publicando periódicamente la producción cientílica enfermera que se va generando en el país.

${ }^{12}$ El número 4 de Híades (pp. 11-23) recoge un total de algo más de mil referencias bibliográficas sobre el quehacer enfermero en la historia: obras monográficas publicadas, artículos sobre distintos aspectos del trabajo desarrollado por el enfermero y la matrona, referencias a actas de Jornadas y Congresos de historia de la Enfermería y la Medicina, etc. En su sección Fichas Bibliográficas para la Historia de la Enfermería, la revista hace una recensión de aquellas obras más importantes que con una finalidad docente se han ido utilizando para la formación del profesional enfermero (Instrucción de Enfermeros — siglo XVII-; Directorio de enfermeros — siglo XVIIl-; Cartilla nueva, útil y necessaria para instruirse las Matronas — siglo XVIII-, etc.).
} 
unas inquietudes surgidas de la confluencia de una serie de circunstancias que propiciaron su aparición. Sus páginas están abiertas a cuantos investigadores deseen exponer tanto las líneas de investigación emprendidas como los resultados obtenidos. Asimismo, Híades pretende constituirse en un foro de encuentro permanente para todos aquellos amantes de la historia de la profesión enfermera investigadores, profesores de la disciplina, profesionales, lectores en general_- que ven en ella una forma de adquirir una formación integral. Por último, Hiades apuesta por el futuro. Pensamos que las nuevas tecnologías van a jugar, están jugando ya, un extraordinario papel en la investigación del pasado enfermero: acceso a archivos y bibliotecas, empleo de bases de datos nacionales e internacionales, intercambio con otros investigadores de zonas geográficas lejanas....

\section{Apéndice}

Resultados del estudio cuantitativo sobre Hiades

- Total de números publicados de Híades: 7 (el n. ${ }^{\circ}$ se halla en prensa en la actualidad).

- Total de artículos/colaboraciones: 89.

- N. ${ }^{\circ}$ de autores/colaboradores: 55.

- Procedencia de los trabajos: 20 provincias distintas. El lugar de procedencia y número de colaboraciones son los siguientes: Sevilla (45); Madrid (7); Cádiz (3); Huelva (3); Granada (2); Santa Cruz de Tenerife (2); Málaga (1); Albacete (1); Palencia (1); Vigo (1); Extremadura (1); Valencia (1); Jaén (1); Mérida (1); Gijón (1); Almería (1); Plasencia (1); Alicante (1); Oviedo (1); Navarra (1).

- Profesión/titulación de los colaboradores: Catedrático de Historia, Profesor/a de Universidad (Historia, Historia de la Ciencia, Medicina), Profesor/a de Escuela Universitaria de Enfermería (Historia de la Enfermería, Fundamentos de Enfermería, Bioética, Materno-Infantil, MédicoQuirúrgica), Profesor/a de Unidad Docente de Matrona, Licenciado en Enfermería, Licenciado en
Antropología, Licenciado en Historia, Licenciado en Derecho, Diplomado en Enfermería, Matrona, Fisioterapeuta, Director/a de Enfermería, Formación Continuada de Hospital, Presidente/a de diversas asociaciones nacionales, Técnico en Estadística.

- Períodos históricos estudiados:

-Anterior al siglo II: 2

-Siglos V-XV: 7

-Siglo XVI: 11

-Siglo XVII: 13

-Siglo XVIII: 10

-Siglo XIX: 14

-Siglo XX: 14

-Recorrido Histórico general: 3

Por períodos históricos:

-Edad Antigua: 2; Edad Media: 7; Edad Moderna: 34; Edad Contemporánea: 28; Recorrido Histórico General: 3.

- Áreas geográficas estudiadas: España (41); Madrid (11); Sevilla (6); Andalucía (4); Cádiz (3); Hispanoamérica (2); Málaga (2); Barcelona (2); Asturias (2); Internacionales (2): Roma/Grecia antiguas; Egipto antiguo (1); Castilla (1); Aragón (1); Zaragoza (1); Jerez de la Frontera (1); Galicia (1); Palencia (1); Canarias (1); Mallorca (1); Extremadura (1); Navarra (1).

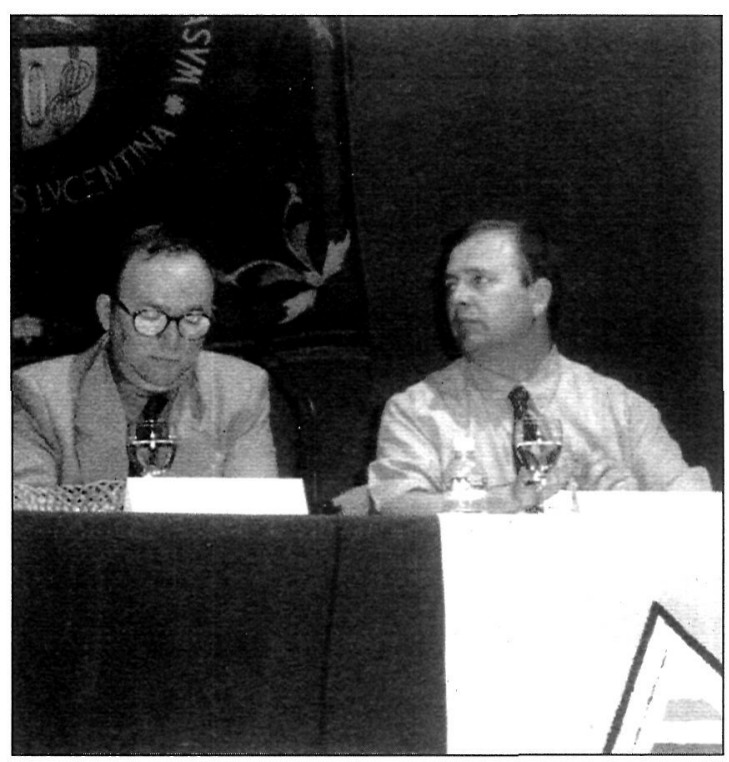

